\title{
Inhibition of Enzyme Activities by 12-Keto Oleic Acid ${ }^{1)}$
}

\author{
Masao Sato and Mitsuru Uchiyama \\ Pharmaceutical Institute, Tohoku University ${ }^{2}$
}

(Received November 2, 1971)

\begin{abstract}
The effect of the long chain keto acid, which is one of the secondary products from oxidative deteriolation of lipids, on the enzyme activity was investigated in vitro. Cholinesterase and succinate dehydrogenase were inhibited more effectively by 12 -keto oleic acid than by linoleic acid, whereas the inhibition of trypsin by linoleic acid was greater than that caused by 12-keto oleic acid. This fact may show that the enzyme inhibition by 12 -keto oleic acid is not merely due to nonspecific denaturation.

The inhibitory effect of 12-keto oleic acid on acetylcholinesterase was not protected by the presence of $\alpha$-tocopherol, while the inhibition by linoleic acid was completely restored when $\alpha$-tocopherol was added simultaneously. When both linoleic and 12-keto oleic acids were added at the same time, the synergistic inhibition was observed, which was partially protected by $a$-tocopherol. Thus the inhibition caused by 12 -keto oleic acid is not only the reflection of the stimulation of lipid peroxidation induced by 12 -keto oleic acid, but the specific irreversible interaction with enzyme protein.
\end{abstract}

It is well known that oxidized fats cause various damages to the physiological constituentes and functions. The essential toxic substance in oxidized fats has been considered to be lipohydroperoxides which will give damages to $\mathrm{SH}$ enzymes, ${ }^{3)}$ cytochrome $\mathrm{C}^{4)}$ and lipoproteins. ${ }^{5}$ Therefore, the toxicity of oxidized fats must be generally enhanced when peroxide value is increased as the time proceeds during oxidation. ${ }^{6)}$ However, it is reported that though peroxide value of oxidized fats decreased, the toxicity did not always decrease. Namely, the change of their peroxide value is not always correlate with that of their oral toxicity. ${ }^{7)}$ It has been generally accepted that lipohydroperoxide itself is hardly absorbed through intestinal wall. These facts reveal that the toxic substance other than lipohydroperoxide will be present in the oxidized fats and it may be absorbed through intestinal wall. The identification of absorbable oxidation products has been made, among which it is known that hydroxy- and epoxy-acids were not toxic. ${ }^{8)} \quad$ As to long chain keto acid, many investigators reported the production of various keto acids in oxidized fats under different conditions. ${ }^{9-11)}$ Some of those are efficiently absorbed through intestinal wall. ${ }^{12}$ In the preceding paper, ${ }^{13}$ ) we reported the promotive activity of long chain keto acid on lipid peroxi-

1) This report has been presented at The 90th Annual Meeting of Pharmaceutical Society of Japan, Sapporo, July, 1970.

2) Location: Aobayama, Sendai.

3) E.D. Wills, Biochem. Pharmc., 7, 7 (1961).

4) I.D. Desai and A.L. Tappel, J. Lipid Res., 4, 204 (1963).

5) T. Nishida and F.A. Kummerow, J. Lipid Res., 1, 450 (1960).

6) N. Matsuo, "Lipids and Their Oxidation," eds by H.W. Schultz, et al., Avi published, Westport, 1962, p. 321 .

7) Y. Ito, K. Isobe, H. Sekita, M. Osawa, M. Takeda, H. Tanabe, S. Nagoya, and T. Kuwamura, J. Food Hygienic Soc. Japan, 11, 268 (1970).

8) N.W. Hanson, Chemistry and Industry, 1964, 1591.

9) G.W. Ellis, Biochemistry, 46, 129 (1950).

10) N.R. Artman and J.C. Alexander, J. Am. Oil Chemist's Soc., 45, 643 (1968).

11) L.R. Wantland and E.G. Perkins, Lipids, 5, 191 (1970).

12) M. Sato and M. Uchiyama, The 89th Annual Meeting of Pharmaceutical Society of Japan, Nagoya, April, 1969.

13) M. Sato and M. Uchiyama, Chem. Pharm. Bull. (Tokyo), 19, 1118 (1971). 
dation. In the present paper, the effect of such long chain keto acid on some enzymes, succinate dehydrogenase, trypsin and cholinesterase, which are all known to be inhibited by linoleic acid or lipid peroxide, was investigated in vitro.

\section{Material and Method}

Preparation of Fatty Acids — - The methods of preparation of ricinoleic, 12-keto oleic and 12-keto stearic acids have been previously described. ${ }^{13}$ ) Pure linoleic acid was prepared by hydrolysis of ethyl linoleate obtained from Ono Seiyaku Co., Ltd. (Osaka) before use. Oleic acid was prepared by the method of Rubin, et al. ${ }^{14)}$

Materials-DL- $\alpha$-Tocopherol was the gift from Eisai Co., Ltd. (Tokyo). Bovine erythrocyte acetylcholinesterase and neotetrazorium chloride were purchased from Sigma Chemical Company. Trypsin was obtained from Tokyo Kasei Co., Ltd. (40000 Fuld-Gross units/g). Glutathione was obtained from Wako Pure Chemical Industries Ltd. (Tokyo). Methyl parathione was obtained from Sumitomo Chemical Industry Ltd. (Osaka) and L-cysteine was obtained from SS Pharmaceutical Co., Ltd. (Tokyo).

Measurement of Enzyme Activity_Succinate-neotetrazolium chloride oxidoreductase (succinate dehydrogenase, E.C. 1.3.99.1) was determined by measuring the amount of formazan formed by reduction of neotetrazolium chloride ${ }^{15}$ ) using mitochondria prepared according to the method of Schneider, et al. ${ }^{16)}$ Fatty acids were added as ethanol solutions giving a final concentration of $4.8 \%$ ethanol. Control experiments using buffer containing $4.8 \%$ ethanol were always carried out testing the effect of these emulsion on enzyme. Preincubation at $37^{\circ}$ for 10 min under air and incubation for 10 min under $\mathrm{N}_{2}$ were carried out.

Acetylcholinesterase (E.C.3.1.1.7) was determined by a modification of the method of Ellman, et al.17) utlizing acetylthiocholine iodide as a substrate. Enzymes were previously incubated with lipids at $37^{\circ}$ for $60 \mathrm{~min}$ before determining the activity. The reaction took place at $30^{\circ}$ in a total volume of $2.9 \mathrm{ml}$ consisting of $0.1 \mathrm{~m}$ phosphate buffer ( $\mathrm{pH} 7.4), 2 \mu$ moles of acetylthiocholine iodide, $0.4 \mu$ mole of $5,5^{\prime}$-dithiobisnitrobenzoic acid (DTNB), varing amount of lipid compounds, $0.2 \%$ Tween 80 and $0.02 \mathrm{mg}$ of crystalline bovine erythrocyte acetylcholinesterase. Progressive formation of yellow pigment by the reaction of released thiocholine with DTNB was followed at $412 \mathrm{~m} \mu$ with a $1.0 \mathrm{~cm}$ light path in Shimazu multiconvertible spectrophotometer Double-40.

Cholinesterase (E.C.3.1.1.8) in human plasma was determined by a modification of the method of Ellman, et al. ${ }^{17)}$ A solution of $8 \mathrm{mg}$ of lyophilized human plasma (Nippon Seiyaku Co., Tokyo) dissolved in $1.0 \mathrm{ml}$ of saline was diluted to $2.0 \mathrm{ml}$ with $0.1 \mathrm{M}$ phosphate buffer $(\mathrm{pH} 7.4)$. To this solution was added $0.04 \mathrm{ml}$ of an ethanol solution of lipid and the mixture was placed in a bath of $25^{\circ}$ and incubated for 30 min. Thereafter $25 \mu$ moles of acetylthiocholine iodide dissolved in $0.5 \mathrm{ml}$ of $0.1 \mathrm{M}$ phosphate buffer ( $\mathrm{pH} 8.2$ ) was added as a substrate and maintained at $25^{\circ}$ for $3 \mathrm{~min}$. The reaction was stopped by the addition of $10 \mu$ moles of eserine and then $1 \mu$ mole of DTNB dissolved in $0.5 \mathrm{ml}$ of $0.1 \mathrm{~m}$ phosphate buffer (pH 7.4) was. added. The solution was diluted with $5 \mathrm{ml}$ of distilled water and the optical density was read at $412 \mathrm{~m} \mu$. A calibration curve was prepared by using reduced glutathione.

Trypsin (E.C.3.4.4.4) activity was measured according to Kunitz. ${ }^{18}$ ) Fatty acids were added as ethanol solutions giving a final concentration of $2.4 \%$ ethanol. The amount of alcohol thus added to reaction mixture was found to be non-effect in control experiment. Preincubation at $37^{\circ}$ for 30 min and incubation for $20 \mathrm{~min}$ were carried out with constant shaking. The activity was determined by measuring the optical density at $280 \mathrm{~m} \mu$.

\section{Result}

\section{Effect of Various Fatty Acids on Some Enzymes}

The effect of emulsions containing $1 \times 10^{-3} \mathrm{M}$ stearic, oleic, linoleic, 12-keto oleic (12$\mathrm{KOA}$ ), 12-keto stearic and ricinoleic acids in $0.1 \mathrm{~m}$ phosphate buffer ( $\mathrm{pH} 7.4$ ) on bovine erythrocyte acetylcholinesterase (BE-AChE) and human plasma cholinesterase (HP-ChE) was examined. The results are shown in Table I. BE-AChE was inhibited to much greater extent by $12-\mathrm{KOA}$ than by linoleic acid. 12-Keto stearic and oleic acids were found to be only

14) L.J. Rubin and W. Paisley, J. Am. Chem. Soc., 37, 300, (1960).

15) A. Ogamo, Y. Suzuki, and S. Okui, J. Biochem., 60, 197 (1966).

16) G.H. Hogeboon and W.C. Shneider, J. Biol. Chem., 196, 111 (1952).

17) G.L. Ellman, K.D. Courtnery, V. Andres, Jr., and R.M. Featherstone, Biochem. Pharmac., 7, 88 (1961).

18) K. Kunitz, "Method in Enzymology," Vol. 2, Academic Press Inc., New York, 1955, p. 26. 
TABLE I. Effect of Various Fatty Acids on Bovine Erythrocyte Acetylcholinesterase (BE-AChE) and Human Plasma Cholinesterase (HP-ChE)

\begin{tabular}{lcc}
\hline \multicolumn{1}{c}{ Fatty acid } & \multicolumn{2}{c}{ Relative activity (\%) } \\
& BE-AChE & HP-ChE \\
\hline None & 100 & 100 \\
Stearic acid & 100 & - \\
Oleic acid & 92.7 & - \\
Linoleic acid & 82.9 & 68.6 \\
12-Keto oleic acid & 76.8 & 92.1 \\
12-Keto stearic acid & 98.4 & 89.5 \\
Ricinoleic acid & 88.7 & \\
\end{tabular}

Enzyme was preincubated with fatty acid in $0.1 \mathrm{M}$ phosphate buffer, $\mathrm{pH} 7.4$, at $37^{\circ}$ for $60 \mathrm{~min}$ (BE$\mathrm{AChE}$ ) or $30 \mathrm{~min}$ (HP-ChE). $1 \mathrm{~mm}$ of fatty acid was used in ethanolic solution (HP-ChE) or suspension (BE-AChE). Values are an average of duplicate determination in a representative experiment performed on two (BE-AChE) or three (HP-ChE) separate occasions.

slightly inhibitive. The similar result was obtained when HP-ChE was tested. This inhibition on cholinesterase may connect with the presence of carbonyl and double bond at the same time.

The influence of fatty acids in vitro on succinate dehydrogenase of rat liver mitochondria were almost identical at the lower concentration and these results will be explained by the detergent property of fatty acid and subsequent swelling of mitochondria. But, the higher concentration of $12-\mathrm{KOA}$ produced the stronger inhibition that the other fatty acids in the same concentration (Table II).

TABlE II. Effect of Various Fatty Acids on Succinate-Neotetrazolium Chloride Oxidoreductase of Rat Liver Mitochondria

\begin{tabular}{lcc}
\hline \multicolumn{1}{c}{ Fatty acid } & \multicolumn{2}{c}{ Enzyme activity } \\
& $1 \times 10^{-3} \mathrm{M}$ & $2.5 \times 10^{-3} \mathrm{M}$ \\
\hline None & 1.00 & 1.03 \\
Stearic acid & 0.38 & 0.34 \\
Oleic acid & 0.41 & 0.37 \\
Linoleic acid & 0.39 & 0.32 \\
12-Keto oleic acid & 0.29 & 0.16 \\
12-Keto stearic acid & 0.46 & 0.44 \\
Ricinoleic acid & 0.36 & 0.33 \\
\hline
\end{tabular}

The basal medium consisted of $100 \mu$ moles of phosphate buffer ( $\mathrm{pH} \mathrm{7.4),} 100 \mu$ moles of sodium succinate and fatty acids in a total volume of $1.2 \mathrm{ml}$. Mitochondria in the reaction mixture were preincubated with fatty acid at $37^{\circ}$ for $10 \mathrm{~min}$ under air. The reaction was started by the addition of succinate and neotetrazolium salt. Incubation was carried out for 10 min under $\mathrm{N}_{2}$. Specific activity was expressed as $\mathrm{m} \mu \mathrm{moles}$ formazan formed $/ \mathrm{min} / \mathrm{mg}$ protein.

The susceptibility of trypsin against fatty acids was different from above three enzymes, namely linoleic or 12-keto stearic acid was more inhibitory than 12-KOA (Table III).

Changes of the activity of $\mathrm{BE}-\mathrm{AChE}$ by increasing the concentration of $12-\mathrm{KOA}$ are shown in Fig. 1. 12-KOA gave a powerful inhibition at the specified concentration at which the inhibition increased progressively with the increase of concentration of 12-KOA.

\section{Effect of $\alpha$-Tocopherol on 12-KOA-inactivation of Cholinesterase}

It is reported that the inhibition of bovine red cell $\mathrm{AChE}$ and intact human erythrocyte is caused by lipid peroxide during ultraviolet radiation. ${ }^{19}$ ) In the present paper, crystalline

19) B.W. O’Malley, C.E. Mengel, W.D. Meriwether, and L.G. Zilkle, Jr., Biochemistry, 5, 40 (1966). 
TABLE III. Effect of Various Fatty Acids on Trypsin Activity

\begin{tabular}{lc|cc}
\hline \hline Additive & Relative activity (\%) & Additve & Relative activity (\%) \\
\hline None & 100 & 12-Keto oleic acid & 89.1 \\
Stearic acid & 90.7 & 12-Keto stearic acid & 63.3 \\
Oleic acid & 81.7 & Ricinoleic acid & 91.3 \\
Linoleic acid & 72.6 & & \\
\hline
\end{tabular}

$1 \mathrm{~mm}$ of each fatty acid in ethanolic solution was added. Preincubation was carried out at $37^{\circ}$ for 30 min with constant shaking. Values are an average of duplicate determination in a representative experiment performed on four separate occasions.

TABLE IV. Effect of $\alpha$-Tocopherol, 12-Keto oleic Acid and Linoleic Acid on Bovine Erythrocyte Acetylcholinesterase

\begin{tabular}{lc}
\hline \multicolumn{1}{c}{ Additive } & Activity $(\mathrm{m} \mu$ moles $/ \mathrm{min})$ \\
\hline None & $27.3(100)$ \\
Linoleic acid & $20.1(74.0)$ \\
Linoleic acid $+\alpha$-tocopherol & $27.3(100)$ \\
12-Keto oleic acid & $18.6(68.2)$ \\
12-Keto oleic acid $+\alpha$-tocopherol & $15.6(57.0)$ \\
Linoleic acid +12 -keto oleic acid & $0.1\left(\begin{array}{c}0.4) \\
\text { Linoleic acid }+12 \text {-keto oleic acid }+\alpha \text {-tocopherol }\end{array}\right.$ \\
\end{tabular}

$1 \times 10^{-3} \mathrm{M}$ of 12 -keto oleic, linoleic acids and $\alpha$-tocopherol was used. Preincubation was carried out at $37^{\circ}$ for $60 \mathrm{~min}$ with constant shaking. Activity is expressed as $\mathrm{m} \mu$ moles of acetylthiochloline iodide hydrolyzed/ min. Figures in parenthesis indicate percent of corresponding control. Values are an average in representative experiment performed on three separate occasions.

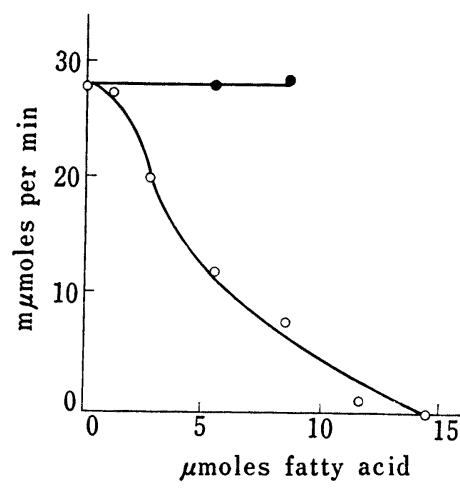

Fig. 1. Changes in the Activity of Bovine Erythrocyte Acetylcholinesterase by the addition of 12-Keto oleic Acid

The enzyme in $0.1 \mathrm{~m}$ phosphate buffer, $\mathrm{pH} 7.4$, was incubated for $60 \mathrm{~min}$ with fatty acid suspended with $0.2 \%$ Tween 80 . Activity is expressed as $\mathrm{m} \mu$ moles of acetylthiochloline iodide hydrolyzed per min. $\bigcirc-\bigcirc: 12$-keto oleic acid

stearic acid

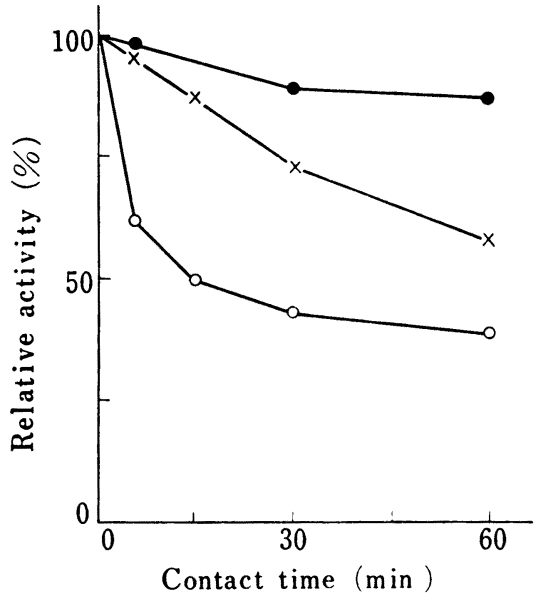

Fig. 2. Changes in the Activity of Bovine Erythrocyte Acetylcholinesterase by the Duration of Preincubation

$\mathrm{BE}-\mathrm{AChE}$ was incubated with 12-keto oleic acid or methyl parathione in $0.1 \mathrm{M}$ phosphate buffer, $\mathrm{pH} 7.4$ with constant shaking. 12-Keto oleic acid ( $1 \mathrm{~mm}$ ) and methyl parathione $(0.1 \mathrm{~mm})$ were added in emulsion. - : control, $x-12$ keto oleic acid, $\bigcirc-\bigcirc:$ methyl parathione 
BE-AChE was weakly inhibited by linoleic acid. Moreover, because the inhibitory effect of linoleic acid was completely recovered by the addition of $\alpha$-tocopherol, the inhibition must be caused by lipohydroperoxide produced from linoleic acid during incubation (Table IV). However, the inhibition by 12 -KOA was not prevented by the addition of $\alpha$-tocopherol. No inhibition by $\alpha$-tocopherol itself was recognized. When both linoleic acid (1 mM) and 12-KOA (1 $\mathrm{mm}$ ) were added at the same time, enzyme activity was completely inhibited, which was far stronger than the effect brought by $2 \mathrm{~mm}$ of sole fatty acid and only partially restored by $\alpha$-tocopherol.

In human plasma cholinesterase, the similar result was observed (Table V). The synergistic effect by the presence of linoleic acid and 12-KOA, however, was not so remarkably. The inhibition by $12-\mathrm{KOA}$, in this case, was slightly recovered by the addition of higher concentration of $\alpha$-tocopherol, which suggests the partial contribution of lipohydroperoxide formed from unsaturated fatty acids in human plasma.

TABLE V. Effect of Linoleic acid, 12-KOA and $a$-Tocopherol on Human Plasma Cholinesterase

\begin{tabular}{|c|c|c|c|}
\hline \multirow{2}{*}{ Additive } & \multicolumn{2}{|c|}{ Relative activity (\%) } & \multirow[b]{2}{*}{$\mathrm{C}$} \\
\hline & A & B & \\
\hline None & 100 & 100 & 100 \\
\hline Linoleic acid & 88.2 & 70.0 & 84.6 \\
\hline 12-KOA & 65.7 & 38.5 & 64.8 \\
\hline Linoleic acid + 12-KOA & 48.5 & 28.6 & - \\
\hline Linoleic acid $+\alpha$-tocopherol & 100 & 一 & 100 \\
\hline Linoleic acid +12 -KOA $+a$-tocopherol & 45.0 & 29.7 & - \\
\hline \multirow[t]{3}{*}{$12-\mathrm{KOA}+\alpha$-tocopherol } & 51.3 & - & $60.3\left(5 \times 10^{-3} \mathrm{M}\right)$ \\
\hline & - & - & $66.4\left(2.5 \times 10^{-2} \mathrm{M}\right)$ \\
\hline & - & - & $72.0\left(5 \times 10^{-2} \mathrm{M}\right)$ \\
\hline$\alpha$-Tocopherol & - & 100 & - \\
\hline
\end{tabular}

\footnotetext{
A: $1 \times 10^{-3} \mathrm{M}$ of each fatty acid and $5 \times 10^{-8} \mathrm{M}$ of $\alpha$-tocopherol were used. Values are an average of determination in a experiment performed on six separate occasions.

B: $2.7 \times 10^{-3} \mathrm{M}$ of each fatty acid and $5 \times 10^{-8} \mathrm{M}$ of $\alpha$-tocopherol were used. Values are an average of determination in a experiment performed on two separate occasions.

C: $1 \times 10^{-3} \mathrm{M}$ of each fatty acid was used. Values in brackets indicate concentration of $\alpha$-tocopherol.

The enzyme preparation was incubated with fatty acids and $a$-tocopherol for $30 \mathrm{~min}$ at $37^{\circ}$ before determining the activity. As controls, the enzyme preparation was incubated for $30 \mathrm{~min}$ in the absence of lipid. The assay method was described in method section.
}

\section{Properties of 12-KOA Inactivation}

The effect of preincubation time on inhibition of $\mathrm{BE}-\mathrm{AChE}$ was investigated at $37^{\circ}$ (Fig. 2). The slight decrease of activity was found in the absence of inhibitors. The inhibition by $12-\mathrm{KOA}$ increased proportionally with the increase of the period of preincubation. The inhibition by methyl parathione reached the maximum at $15 \mathrm{~min}$ of contact time.

To determine whether 12-KOA inhibition is reversible, an effort was made to overcome the inhibition by dilution. The system used was similar to that used by Christner, Nand and Mhatre to study the reversal of inhibition of $\beta$-glucuronidase by cummen hydroperoxide. ${ }^{20}$ ) As shown in Table VI, it is evident that enzyme could not be released from enzyme-inhibitor complex by dilution, which reveals the inhibition is irreversible.

Since it is known that the sulfhydryl enzymes are most susceptible to inactivation by lipid peroxide and the inhibition is protected by $\mathrm{SH}$ compound, ${ }^{3)}$ effect of $\mathrm{SH}$ reagents for inhibition of $12-\mathrm{KOA}$ was investigated. The preincubation of $12-\mathrm{KOA}$ with glutathione was not effective to prevent the inhibition even if the molar ratio of glutathione: $12-\mathrm{KOA}$ was increased

20) J.E. Christner, S. Nand, and N.S. Mhatre, Biochem. Biophys. Res. Commun., 38, 1098 (1970). 
TABLE VI. Reversibility of 12-KOA Inhibition of Bovin Erythrocyte Acetylcholinesterase by Dilution

\begin{tabular}{|c|c|c|c|c|c|c|}
\hline \multirow{2}{*}{ Experiment } & \multicolumn{2}{|c|}{ Pre-assay mixture } & \multicolumn{2}{|c|}{ Assay mixture } & \multirow[b]{2}{*}{ Activity } & \multirow{2}{*}{$\begin{array}{c}\text { Inhibition } \\
(\%)\end{array}$} \\
\hline & $\begin{array}{c}\text { Enzyme } \\
(\mu \mathrm{g})\end{array}$ & $\underset{(\mathrm{mm})}{\text { Inhibitor }}$ & $\underset{(\mu \mathrm{g})}{\text { Enzyme }}$ & $\underset{(\mathrm{m} M)}{\text { Inhibitor }}$ & & \\
\hline 1 & 20 & 0 & 18.6 & 0 & 33.2 & - \\
\hline 2 & 4 & 0 & 3.7 & 0 & 5.49 & - \\
\hline 3 & 20 & 2 & 18.6 & 1.86 & 9.25 & 72.2 \\
\hline 4 & 4 & 2 & 3.7 & 1.86 & 1.99 & 63.8 \\
\hline 5 & 20 & 0.4 & 18.6 & 0.37 & 34.1 & 0 \\
\hline 6 & 4 & 0.4 & 3.7 & 0.37 & 6.66 & 0 \\
\hline 7 & 20 & 2 & 3.7 & 0.37 & 16.6 & 68.7 \\
\hline
\end{tabular}

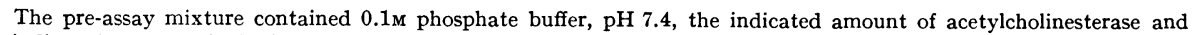
the indicated amount of inhibitor (12-keto oleic acid) suspended with Tween 80 in a final volume of $2.7 \mathrm{ml}$. The mixture was allowed to incubate $30 \mathrm{~min}$ at $37^{\circ}$ after addition of the inhibitor. In experiment 1 to $6,0.1 \mathrm{ml}$ of $20 \mathrm{~mm}$ acetylthiocholine iodide was added to the pre-assay mixture to yield the assay mixture. In last experiment, $2.7 \mathrm{ml}$ of pre-assay mixture was diluted five fold in a solution containing the same concentration of buffer. Substrate was added and acetylthiocholine iodide hydrolyzed was measured in a cuvette as the absorbance change at $412 \mathrm{~m} \mu$ with a $1.0 \mathrm{~cm}$ light path. Activity was expressed as $\mathrm{m} \mu$ moles of acetylthiocholine iodide hydrolyzed per min.

(Table VI). 12-KOA was found to be more inhibitory on succinate dehydrogenase in rat liver mitochondria than other fatty acids (Table II). The inhibition was partially reversed by the addition of excess cysteine. If the concentration of cysteine was much greater, e.g. $10 \mathrm{~mm}$, the recovery of enzyme activity reached to $40 \%$ (Table VIII).

TABle VII. Effect of GSH and 12-KOA on Human Plasma Cholinesterase

\begin{tabular}{ccc}
\hline \hline \multicolumn{2}{c}{ Molecular ratio } \\
$12-$ Keto oleic acid $:$ Glutathione & Relative activity (\%) \\
\hline- & - & 100 \\
1 & - & 78.0 \\
1 & 3 & 78.2 \\
1 & 5 & 78.5 \\
1 & 8 & 76.2 \\
\hline
\end{tabular}

Enzyme activity was determined by a modification of the method of Hestrin. Glutathione in contact with $6 \times 10^{-4} \mathrm{M}$ 12-keto oleic acid $(12-\mathrm{KOA})$ for $30 \mathrm{~min}$ before addition of enzyme.

TABLE VIII. Effect of 12-KOA and L-Cysteine on Rat Liver Mitochondria Succinate-Neoterazolium Chloride Oxidoreductase

\begin{tabular}{ccc}
\hline 12-Keto oleic acid $(\mathrm{M})$ & L-Cysteine $(\mathrm{M})$ & Activity $(\%)$ \\
\hline- & - & 100 \\
$10^{-3}$ & - & 17.8 \\
$10^{-3}$ & $1 \times 10^{-3}$ & 21.8 \\
$10^{-3}$ & $2.5 \times 10^{-3}$ & 20.6 \\
$10^{-3}$ & $5 \times 10^{-3}$ & 34.5 \\
$10^{-3}$ & $7.5 \times 10^{-3}$ & 45.0 \\
$10^{-3}$ & $1 \times 10^{-2}$ & 59.3 \\
\hline
\end{tabular}

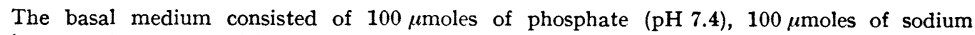
succinate and other additions in a total volume of $1.72 \mathrm{ml}$. 12-KOA and L-cysteine were preincubated at $37^{\circ}$ for $30 \mathrm{~min}$ afterthat with mitochondria for $10 \mathrm{~min}$. 


\section{Discussion}

In the present paper, effect of $12-\mathrm{KOA}$ and the related fatty acids on enzyme activities was investigated. The inhibition pattern of enzyme by $12-\mathrm{KOA}$ described in these results showed two cases: (a) inhibition by 12-KOA was much greater than linoleic acid (b) inhibition by linoleic acid was much greater than $12-\mathrm{KOA}$. These results may show that the inhibitory effect by $12-\mathrm{KOA}$ is not merely due to denaturation of protein.

When the same amount of $12-\mathrm{KOA}$ and linoleic acid was incubated with enzyme at the same time, the synergistic inhibition was observed as compared with the inhibition brought by sole fatty acid (Table IV). It is considered that 12-KOA enhances the effect of linoleic acid, presumably through linoleic acid hydroperoxide formed during incubation. In fact, the inhibitory effect of linoleic acid was prevented in the presence of $\alpha$-tocopherol. $\alpha$-Tocopherol also partially restored the enzyme inhibition in the presence both linoleic acid and 12-KOA. But, the enzyme inhibition by $12-\mathrm{KOA}$ was almost not prevented in the presence of $\alpha$-tocopherol. These facts show that the inhibitory effect of $12-\mathrm{KOA}$ described in this work clearly falls into two categories: (1) that is some modification on enzyme protein (direct action) and (2) that is through the promotive effect on peroxidation (indirect action). These are a common observation that the inhibition by oxygenated fats was not completely protected by the addition of $\alpha$-tocopherol in human erythrocyte acetylcholinesterase. ${ }^{19)}$ Moreover, these results also agree with Shauenstein's report ${ }^{21)}$ that glyceraldehyde dehydrogenase and lactate dehydrogenase were largely inhibited by linoleic acid hydroperoxide and at the same time non-peroxidic compounds have also apparent inhibitory activity.

It is considered that the inhibitory effect of fatty acid or fatty acyl CoA, except the effect through peroxide, on enzymes are due to detergent properties. ${ }^{22,23)}$ The inhibitory effect by anionic detergents is strong when $\mathrm{pH}$ of the solution is acidic. ${ }^{24)}$ It is also known that soaps of long chain unsaturated fatty acids are better detergents than those of corresponding saturated fatty acids. ${ }^{25}$ ) In the present paper, since the reaction described in Table I was carried out at neutral $\mathrm{pH}$, the inhibitory effect of $12-\mathrm{KOA}$ could not be applicable to the detergent effect.

Since the inhibitory effect by $12-\mathrm{KOA}$ on succinate dehydrogenase was protected by the addition of excess of cysteine, the inactivation is probably due to modification of $\mathrm{SH}$ group of enzyme protein. Linoleic acid hydroperoxide causes a rapid destruction of SH group of proteins and amino acid and inhibits the activity of $\mathrm{SH}$ enzymes. ${ }^{26,27}$ In fact, succinate dehydrogenase in rat liver and muscle was strongly inhibited when the rats were fed a basal diet containing $5 \%$ of autoxidized ethyl ester of highly unsaturated fatty acids for few days. ${ }^{6}$ ) And, the inhibition of succinate oxidase by lipid peroxide was partially retired by the addition of glutathione. ${ }^{26)}$ We observed that $12-\mathrm{KOA}$ reacts with $\mathrm{SH}$ group of protein and amino acid. ${ }^{28)}$

On the other hand, because the protective effect by $\mathrm{SH}$ compound was not recognized in the case of the inhibition of cholinesterase, it is likely that the inhibition was due to interaction with other moiety of enzyme protein than SH group. The protective effect was not recognized when used BE-AChE as enzyme and various SH compound other than glutathione as protec-

21) E. Shauenstein, J. Lipid Res., 8, 417 (1967).

22) S.V. Pand and K.F. Mead, J. Biol. Chem., 243, 6180 (1968).

23) J.A. Dorsey and J.W. Porter, J. Biol. Chem., 243, 3512 (1968).

24) E.D. Wills, Biochem. J., 57, 109 (1954).

25) T.O. Henderson and J.J. McNeil, Biochem. Biophy. Res. Commun., 25, 662 (1966).

26) A. Ottolenghi, F. Bernheim, and K.W. Wilbur, Arch. Biochem. Biophys., 56, 157 (1955).

27) S.E. Lewis and E.D. Wills, Biochem. Pharmac., 11, 901 (1962).

28) M. Sato and M. Uchiyama, The 19th Meeting of Food Hygienic Society of Japan, Sendai, October, 1969. 
tive agents. Mounter, et al..$^{\mathbf{2 9})}$ proved that cholinesterase are not $\mathrm{SH}$ enzyme in all probability. Moreover, Castro ${ }^{30}$ ) regarded the possibility that the alkylating agents on cholinesterase can be expected to undergo four reactions with protein such as lysine, histidine, tyrosine and methionine residues and considered that a SH group is not involved during the inhibition by alkylating agents and the possibility of reaction on histidine or methionine groups of enzyme has been discussed.

Tappel, et $\left.a l .{ }^{4}\right)$ reported that when linolenic acid peroxide was reacted with cytochrome $\mathrm{C}$, the insoluble polymeric materials were formed and amino acids such as serine, proline and arginine were also destroyed as much as cysteine. Malonaldehyde, end product of lipid peroxide, is probably the reagent responsible for cross-linking of lysine in enzyme protein. ${ }^{31}$ ) As mentioned above, the toxicity of oxygenated fats is not merely due to destruction of $\mathrm{SH}$ group but the destructive effect on various constituents. We preliminarily recognized ${ }^{28}$ ) that 12-KOA decolorized hemoglobin through the destruction of porphyrin when incubated with aqueous solution of hemoglobin at $37^{\circ}(\mathrm{pH} 7.4)$. Generally, straight chain aldehydes combine with protein. ${ }^{32}$ ) $12-\mathrm{KOA}$, as mentioned, reacts with $\mathrm{SH}$ compounds as cysteine and glutathione to decrease free $\mathrm{SH}^{28)}$ The structure of binding products is now under investigation.

29) L.A. Mounter and V.P. Whittaker, Biochemistry, 53, 167 (1953).

30) J.A. Castro, Biochem. Pharmac., 17, 295 (1968).

31) K.S. Chio and A.L. Tappel, Biochemistry, 8, 2827 (1969).

32) K. Sunazaki and N. Matsuo, Seikagaku, 43, 669 (1971). 